\title{
PROCESOS DE SEDIMENTACION EN EMBALSES EN AMBIENTES TROPICALES. ESTUDIOS DE CASOS EN COSTA RICA Y REPUBLICA DOMINICANA
}

\author{
Oscar Jiménez ${ }^{1}$, Hector Daniel Farias ${ }^{2}$, Carlos Rodríguez ${ }^{3}$
}

\begin{abstract}
Resumen:
En este trabajo se describen algunas experiencias sobre la sedimentación en embalses en zonas tropicales, en los que por el importante aporte de sedimentos han requerido medidas particulares para asegurar su desempeño y lograr una vida útil aceptable. El embalse de Cachí en Costa Rica, utilizado para generación eléctrica, en su puesta en marcha en 1966 contaba con un embalse de 54 hm $^{3}$. La cuenca tributaria de $783 \mathrm{~km}^{2}$ tiene una cobertura boscosa del 50\%, y aun así, dadas las altas precipitaciones y pendientes, y adversas condiciones geotectónicas, tiene una producción de sedimentos de alrededor de 1200 ton $/ \mathrm{km}^{2} /$ año. La acumulación de sedimentos ha requerido que desde 1973 anualmente se realicen vaciados de limpieza, operación que ha permitido descargar una gran parte de los sedimentos acumulados y mantener el $\mathbf{8 0} \%$ de volumen original luego de $\mathbf{3 8}$ años de funcionamiento. Por su parte, el embalse de Angostura, situado aguas abajo, y que inició su operación en el 2001, tiene un embalse de $15 \mathrm{hm}^{3}$ y una cuenca de $1463 \mathrm{~km}^{2}$, con un arrastre de sedimentos de $3.4 \times 10^{6}$ t/año (2348 ton/ $/ \mathrm{km}^{2} /$ año). Este gran arrastre, más los vaciados anuales de Cachí que aportan una cantidad adicional de sedimentos, requirieron una estrategia para el manejo de los sedimentos, que incluye la disposición de obras de vaciado y limpieza, la operación coordinada de ambos embalses, y el manejo de niveles para minimizar la deposición. Por su parte, el embalse de Valdesia es uno de los más importantes de la República Dominicana, desde el punto de vista de riego, de generación eléctrica y por un acueducto que suple aproximadamente el $\mathbf{4 0} \%$ del agua potable de la capital. El impacto directo de los huracanes en dicho país ocasiona eventos extremos de precipitación y una muy alta tasa de producción de sedimentación. Como resultado, al cabo de 20 años de operación se ha perdido un $\mathbf{2 5 \%}$ del volumen inicial, poniendo en peligro las obras de toma del acueducto. Las medidas de control han consistido en el dragado a gran escala mediante hidro-succión y la construcción de dos embalses aguas arriba.
\end{abstract}

Palabras clave: Sedimentación, embalses, vaciado, modelo numérico.

\section{INTRODUCCIÓN}

Los embalses representan un recurso fundamental para el adecuado aprovechamiento de los recursos hidráulicos, permitiendo modular el suministro de agua a las necesidades de consumo. Sin ellos, un porcentaje muy grande del agua dulce terminaría sin uso en los oceános, mientras que en el caso de la generación eléctrica, implicaría un uso mucho más intensivo de recursos fósiles.
De acuerdo a los datos de Walling \& Webb (1996), el promedio mundial de producción de sedimentos es de alrededor de 150 ton $/ \mathrm{km}^{2} /$ año. Sin embargo, los diferentes mapas mundiales de producción de sedimentos que se han elaborado, muestran zonas alrededor del arco del Pacífico, los Himalayas y China, con con producciónes mayores a 1000 ton $/ \mathrm{km}^{2}$. Los valores máximos reportados indican producciones específicas mayores a los 10000 ton/ $\mathrm{km}^{2} /$ año (Walling \& Web 1996).

\footnotetext{
${ }^{1}$ P.O. Box 1310-2150, Moravia, Costa Rica: email: osjime@ racsa.co.cr

${ }^{2}$ Instituto de Recursos Hídricos, Univ. Nacional Santiago del Estero (IRHi-FCEyT-UNSE), email: H.D.Farias@members.asce.org

${ }^{3}$ Instituto Costarricense de Electricidad, San José, Costa Rica, email: crodriguezm@ice.go.cr
}

Artículo recibido el 3 de octubre de 2003, recibido en forma revisada el 26 de noviembre de 2004 y aceptado para su publicación el 14 de diciembre de 2004 . Pueden ser remitidas discusiones sobre el artículo hasta seis meses después de la publicación del mismo siguiendo lo indicado en las "Instrucciones para autores". En el caso de ser aceptadas, éstas serán publicadas conjuntamente con la respuesta de los autores. 
Estas zonas presentan condiciones desfavorables relativas a la erodabilidad del terreno, la falta de cobertura vegetal, las altas pendientes, las altas precipitaciónes, la actividad tectónica, y la intensa actividad agrícola, para mencionar las más importantes. Estas áreas de gran producción $\left(>1000\right.$ ton $\left./ \mathrm{km}^{2}\right)$ son apenas el $8.8 \%$ del territorio del planeta, y sin embargo contribuyen con el $69 \%$ de los sedimentos transportados por los ríos (White, 2001). Las estadísticas indican, además, que como resultado de estos procesos, anualmente ocurre una pérdida de almacenamiento de los embalses de entre el 0.5 y $1 \%$, lo que viene a representar la astronómica suma de más de 50 $\mathrm{km}^{3} / \mathrm{año}$.

América Central y el Caribe son parte de esas zonas de gran producción de sedimentos y en donde desafortunadamente no se ha contado con estadísticas fiables sobre sedimentos. Ciertamente, la estimación de la producción de sedimentos en cuencas es una labor difícil y costosa que requiere muchos años de mediciones. Por ejemplo, en Costa Rica no fue sino hasta los años sesentas cuando se inició el muestreos de sedimentos en las principales cuencas. Otros países, como República Dominicana, aun hoy en día no cuentan con este tipo de mediciones, y la poca información sobre sedimentación proviene de batimetrías en embalses que han sufrido colmatación. Dado lo anterior, no es de extrañar que muchas de las obras hidraúlicas actualmente en operación en esta zona del planeta fueron diseñadas y construidas utilizando criterios extrapolados de otras zonas que consideraban producciones de sedimentos apenas una fracción de lo que la experiencia posterior ha mostrado.

El objetivo de este artículo es mostrar algunas experiencias seleccionadas con embalses que han sufrido problemas de sedimentación, y para los cuales se han tenido que adoptar diferentes tipos de medidas de mitigación y control. Estos problemas no son únicos de Centroamérica y el Caribe, pues por ejemplo, los países andinos también tienen presentan dificultades similares de gran producción de sedimentos y poca información. En el caso de Costa Rica y en mayor medida la Rep. Dominicana, la situación es más compleja por la ocurrencia de fenómenos meteorológicos extremos, como lo son los huracanes, que aunados a topografías muy abruptas, mal uso del suelo, y condiciones geológicas desfavorables, inciden en tasas de sedimentación muy altas.

\section{La Sedimentación en Costa Rica y República Dominicana}

Costa Rica es un país de apenas $51,100 \mathrm{~km}^{2}$, atravesado por un sistema montañoso con cumbres que alcanzan los $3800 \mathrm{msnm}$, altas precipitaciones que varían entre 1500 y $8000 \mathrm{~mm} /$ año (promedio de $3500 \mathrm{~mm} / \mathrm{año}$ ), y ríos cortos y torrenciales que drenan cuencas relativamente pequeñas (500 a $5000 \mathrm{~km}^{2}$ ). En la Fig. 1 se muestra la ubicación de la cuenca del río Reventazón, en el que se encuentran los embalses de Cachí y Angostura.

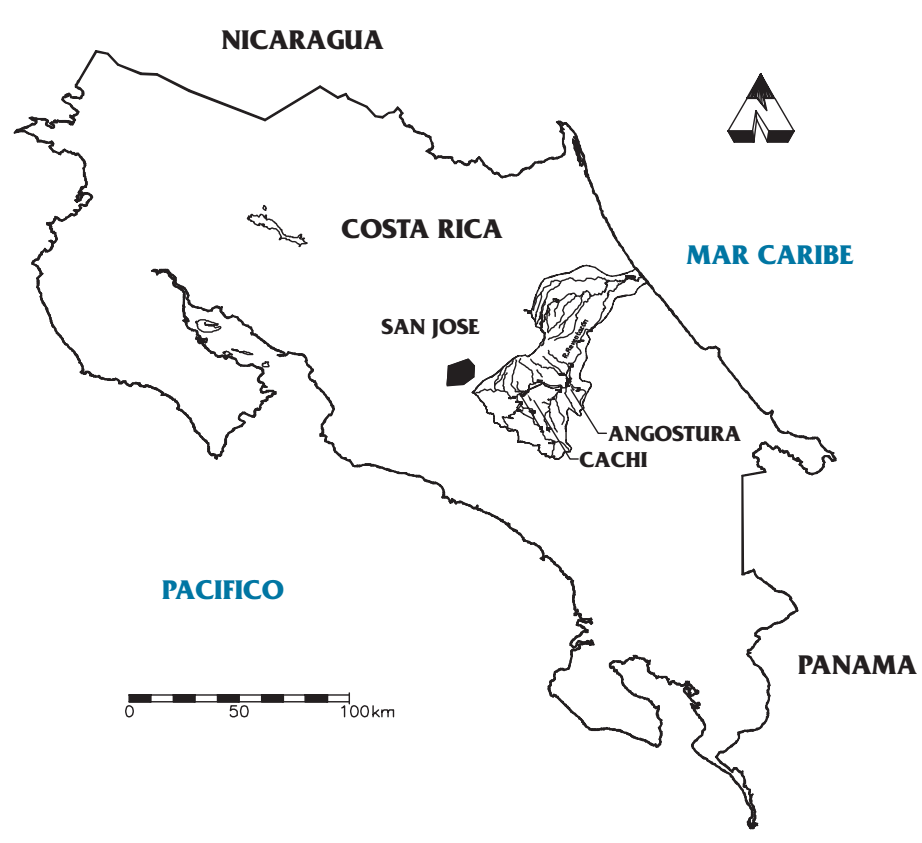

Figura 1. Cuenca del río Reventazón, Costa Rica

En la Tabla 1 se muestran los principales embalses de Costa Rica, cuyo uso fundamental es la generación hidroeléctrica. Este tipo de generación es el principal recurso energético renovable de ese país pues contribuye con un $80 \%$ de la electricidad. Gracias a ello, y en menor grado a generación geotérmica y eólica, más del 95\% de la producción de electricidad se basa en fuentes renovables, lo que ha significado una gran seguridad económica y energética. No se indican en la tabla, pero también existen una cantidad importante de pequeños embalses con volumenes de 50000 a $500000 \mathrm{~m}^{3}$, que se utilizan para regulación diaria en la generación eléctrica. Aparte del embalse de Arenal, de tipo multianual, el resto se trata de embalses relativamente pequeños, y por lo tanto, muy expuestos a la sedimentación. 
Tabla 1. Principales embalses de Costa Rica

\begin{tabular}{|c|c|c|c|c|c|c|c|c|c|}
\hline Embalse & $\begin{array}{c}\text { Año Inicio } \\
\text { Operación }\end{array}$ & $\begin{array}{c}\text { Area de } \\
\text { Cuenca } \\
\mathbf{( k m 2 )}\end{array}$ & $\begin{array}{c}\text { Caudal } \\
\text { Medio } \\
\mathbf{( m 3 / s )}\end{array}$ & $\begin{array}{c}\text { Volumen } \\
\text { Original } \\
\mathbf{( h m 3 )}\end{array}$ & $\begin{array}{c}\text { Volumen } \\
\text { Sedimentado } \\
\mathbf{( h m 3 )}\end{array}$ & $\begin{array}{c}\text { Razón de } \\
\text { Almacen } \\
\mathbf{m 3 / m 3}\end{array}$ & $\begin{array}{c}\text { Porcentaje } \\
\text { Perdido \% }\end{array}$ & $\begin{array}{c}\text { Producción } \\
\text { Sedimentos } \\
\text { (m3/km2/ } \\
\text { año) }\end{array}$ & $\begin{array}{c}\text { Pérdida } \\
\text { Anual \% }\end{array}$ \\
\hline Cachí & 1966 & 783 & 53.9 & 54.0 & 12.0 & 57.5 & 22.2 & 1200 & 0.6 \\
\hline Arenal & 1979 & 515.5 & 47.9 & 1901.0 & 10.0 & 4610 & 0.5 & 800 & 0.0 \\
\hline $\begin{array}{c}\text { Ventanas } \\
\text { Garita }\end{array}$ & 1987 & 820.6 & 33.0 & 0.7 & 0.7 & 1.5 & 100.0 & 531 & 7.7 \\
\hline Angostura & 2001 & 1463 & 105.9 & 17.2 & 1.4 & 5.0 & 8.2 & 2348 & 2.7 \\
\hline Peñas Blancas & 2002 & 156.5 & 22.0 & 3.3 & 1.4 & 18.1 & 42.3 & 1175 & 14.1 \\
\hline
\end{tabular}

Nota: Razón de almacenamiento=capacidad total/ingreso de sedimentos anuales

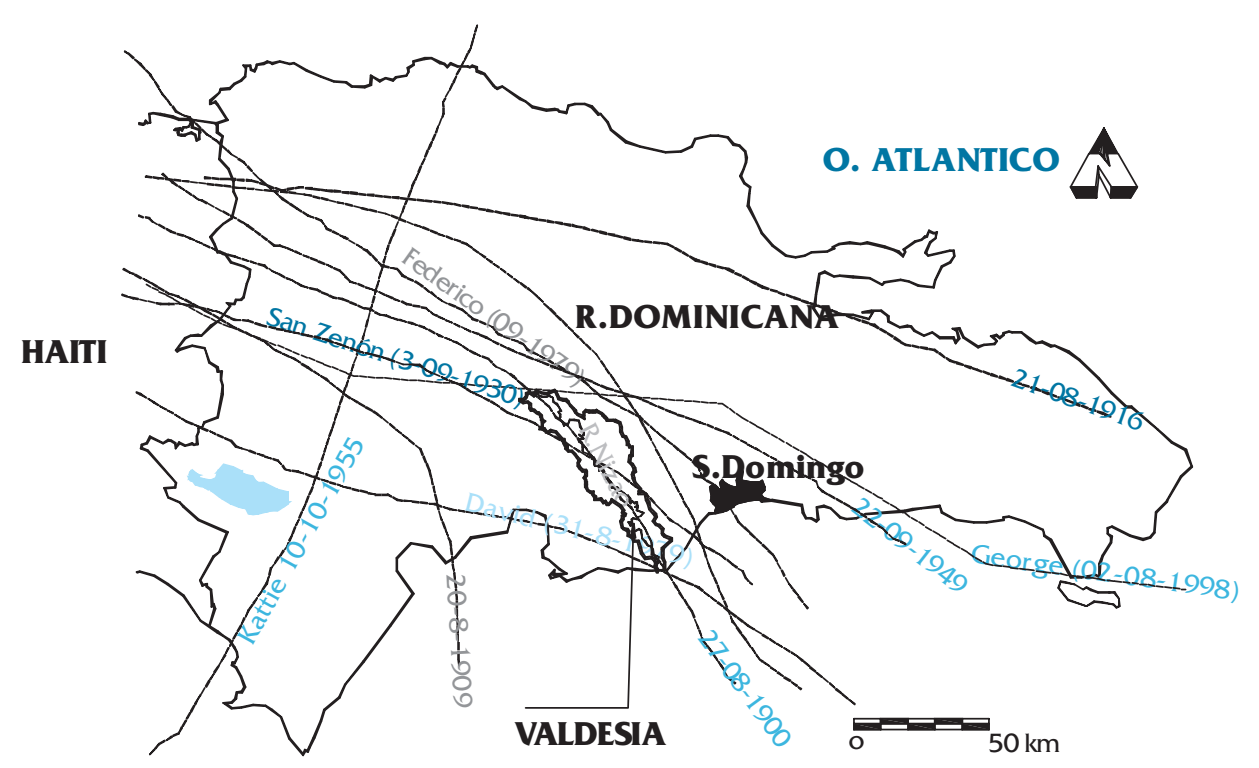

Figura 2. Cuenca del río Nizao, República Dominicana y trayectorias de principales huracanes en el siglo XX

Por su parte, República Dominicana, tiene un área similar de $48,440 \mathrm{~km}^{2}$, y presenta un sistema montañoso con elevaciones de hasta $3000 \mathrm{msnm}$. Las precipitaciones medias oscilan entre $600 \mathrm{y}$ $3000 \mathrm{~mm}$, siendo $1500 \mathrm{~mm}$ el valor medio en el territorio. Sin embargo, entre 1887 y 1990, 46 huracanes pasaron cerca o sobre el país (Nagle, 1997), y cuando inciden directamente ocasionan precipitaciones que en muchos casos exceden los $500 \mathrm{~mm}$ en 48 horas. Algunas de estas trayectorias se muestran en la Fig. 2, junto con la cuenca del río Nizao, en la que se encuentran los embalses de Valdesia, Aguacate y Jigüey.

En la Tabla 2 se detallan los principales embalses de la República Dominicana, con usos múltiples. En las zonas de bajas precipitaciones de este país los embalses juegan un papel muy importante para el suministro de riego, agua potable y en menor grado generación eléctrica.

Tabla 2. Embalses de República Dominicana

\begin{tabular}{|c|c|c|c|c|c|c|c|c|c|}
\hline Embalse & $\begin{array}{l}\text { Año Inicio } \\
\text { Operación }\end{array}$ & $\begin{array}{c}\text { Area de } \\
\text { Cuenca } \\
\text { (km2) }\end{array}$ & $\begin{array}{l}\text { Caudal } \\
\text { Medio } \\
\text { (m3/s) }\end{array}$ & $\begin{array}{c}\text { Volumen } \\
\text { Original } \\
\text { (hm3) }\end{array}$ & $\begin{array}{l}\text { Volumen } \\
\text { Sedimentado } \\
\text { (hm3) }\end{array}$ & $\begin{array}{c}\text { Razón de } \\
\text { Almacen } \\
\text { m3/m3 }\end{array}$ & $\begin{array}{l}\text { Porcentaje } \\
\text { Perdido \% }\end{array}$ & $\begin{array}{c}\text { Producción } \\
\text { Sedimentos } \\
\text { (m3/km2/ } \\
\text { año) }\end{array}$ & $\begin{array}{l}\text { Pérdida } \\
\text { Anual \% }\end{array}$ \\
\hline Tavera & 1973 & 785 & 28.3 & 173.0 & 36 & 96 & $21 \%$ & 2287 & $1.0 \%$ \\
\hline Valdesia & 1976 & 887 & 21.4 & 186.0 & 49 & 61 & $26 \%$ & 3417 & $1.6 \%$ \\
\hline Rincón & 1978 & 178 & 10.0 & 74.5 & 14 & 83 & $19 \%$ & 5056 & $1.2 \%$ \\
\hline Sabana Yegua & 1979 & 1676 & 18.0 & 479.9 & 58 & 108 & $12 \%$ & 2644 & $0.9 \%$ \\
\hline Sabaneta & 1980 & 464 & 7.7 & 76.5 & 13 & 108 & $18 \%$ & 1520 & $0.9 \%$ \\
\hline Hatillo & 1980 & 1190 & 43.6 & 441.0 & 66 & 94 & $15 \%$ & 3944 & $1.1 \%$ \\
\hline Jigüey & 1992 & 537 & 11.0 & 167.2 & nd & 115 & nd & 2700 & nd \\
\hline Aguacate & 1992 & 747 & 15.1 & 4.3 & nd & 2 & nd & 2664 & nd \\
\hline
\end{tabular}


Los embalses indicados no pretenden ser una lista exhaustiva, sino mostrar aquellos casos en los cuales se cuenta con mayor información, y que se discuten con más detalle adelante. Estas tablas muestran la seriedad del problema, con tasas de pérdida anual de entre 0.9 y $1.6 \%$ anual en el caso de Rep. Dominicana. En el caso de Costa Rica, con embalses más pequeños, se muestran tasas que en algunos casos superan el $10 \%$.

\section{Vida Util y Sedimentación}

Un parámetro básico para juzgar el problema de la sedimentación en embalses es la razón de almacenamiento $\mathrm{Kt}$,

$$
K_{r}=\frac{V}{W_{r}}
$$

en donde $\mathrm{V}$ es la capacidad total del embalse $\left(\mathrm{m}^{3}\right)$, y Ws es la carga anual de sedimentos $\left(\mathrm{m}^{3}\right)$.

Aunque la sedimentación en un embalse es en general un fenómeno complicado, existen varios criterios y procedimientos empíricos que permiten estimaciones prácticas. Los métodos empíricos de Brune (1953) o Churchill et. al (1948), permiten estimar de forma aproximada la eficiencia de atrape de sedimentos a partir de ciertos datos básicos. En este último procedimiento, la eficiencia de atrape depende del parámetro denominado índice de sedimentación, que se define como el tiempo promedio de retención dividido por la velocidad media en el embalse, de forma tal que el parámetro incorpora en alguna medida la forma del mismo.

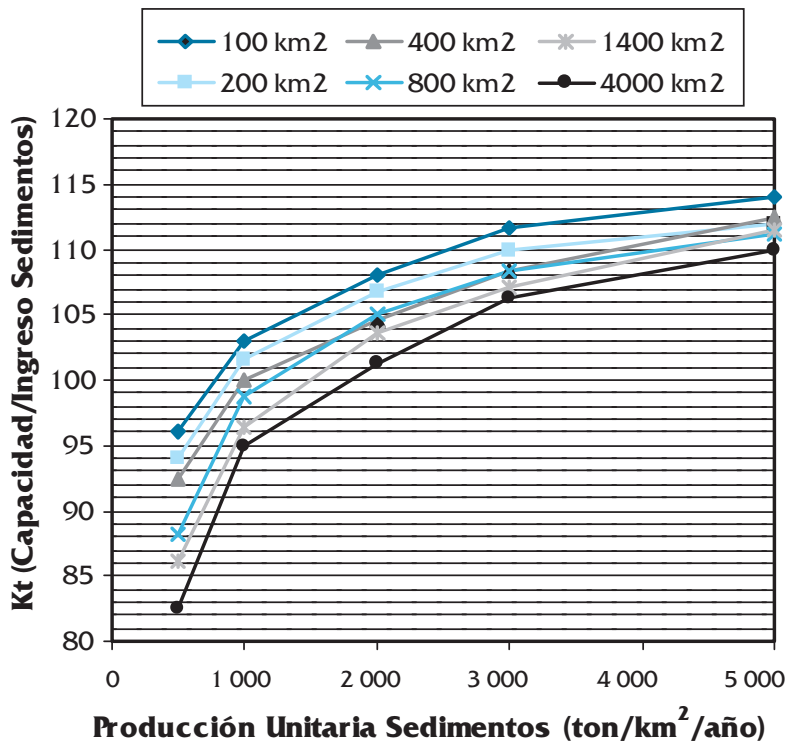

Figura 3. Tamaño del embalse requerido para vida media de 50 años
Utilizando el método de Churchill, se hizo el ejercicio de calcular bajo ciertas condiciones de escorrentía, pendientes de los cursos y suponiendo diferentes valores de producción de sedimentos, el volumen requerido de un embalse que asegura al menos 50 años de vida antes de que se pierda el $50 \%$ de su volumen total, lo que podría denominarse vida media. El procedimiento consiste en calcular la evolución del proceso de llenado, año a año, a partir de la eficiencia de atrape estimada por el método de Churchill. Los resultados se muestran en la Fig. 3.

La Figura 3 muestra que dada una producción unitaria de sedimentos en la cuenca, el tamaño del embalse mínimo se encuentra dentro de un rango estrecho de valores de $\mathrm{K}_{\mathrm{t}}$ entre 85 y 110. Para los valores usuales de producciones unitarias en Costa Rica y República Dominicana (entre 1500 y 5000 ton/ $\mathrm{km}^{2} /$ año), los tamaños mínimos de embalses deben tener valores de $\mathrm{K}_{\mathrm{t}}$ mayores que 100 . Estos resultados confirman lo recomendado por los Estándares Nacionales de China que indican que cuando la razón de almacenamiento de un embalse es menor de 100 a 50, la sedimentación debe considerarse como un problema muy serio y debe estudiarse cuidadosamente (Tan 1994).

Otra forma interesante de representar estos resultados es mediante la capacidad de regulación del embalse $\left(_{-\mathrm{E}}\right)$, definido aquí como capacidad total entre la escorrentía media anual. Esto se muestra en la Fig. 4. En este caso los resultados dependen de la escorrentía en la cuenca, por lo que esa figura se refiere al caso de Costa Rica con una escorrentía media de $75 \mathrm{l} / \mathrm{s} / \mathrm{km}^{2}$. Se observa que embalses con regulación superior a 0.25 no presentan problemas de sedimentación, aun para tasas altas de arrastre.

\section{Embalse de Cachí}

Un excelente compendio sobre la sedimentación se realizó en 1992 (Jansson \& Rodríguez), cuyo contenido, con algunas actualizaciones se resume a continuación. La planta inició su operación en 1966. Cuenta con una presa de arco de $76 \mathrm{~m}$ de altura con un vertedor de compuertas. El embalse tiene una área de 324 ha y su capacidad original era de 54 millones de $\mathrm{m}^{3}$. Los niveles de operación normales están entre las cotas 990 y 960 msnm. El nivel de la toma de aguas es la cota 936 msnm, muy cerca del fondo del embalse, cota $921.5 \mathrm{msnm}$. A este último nivel se encuentra una descarga de fondo, en lo que originalmente fue el túnel de desvío, de $6.5 \mathrm{~m}$ de diámetro. 
Cuenta con una compuerta de vagón aguas arriba y con una compuerta radial aguas abajo. Un túnel y una tubería de presión alimentan la central con una capacidad total de 105 MW.

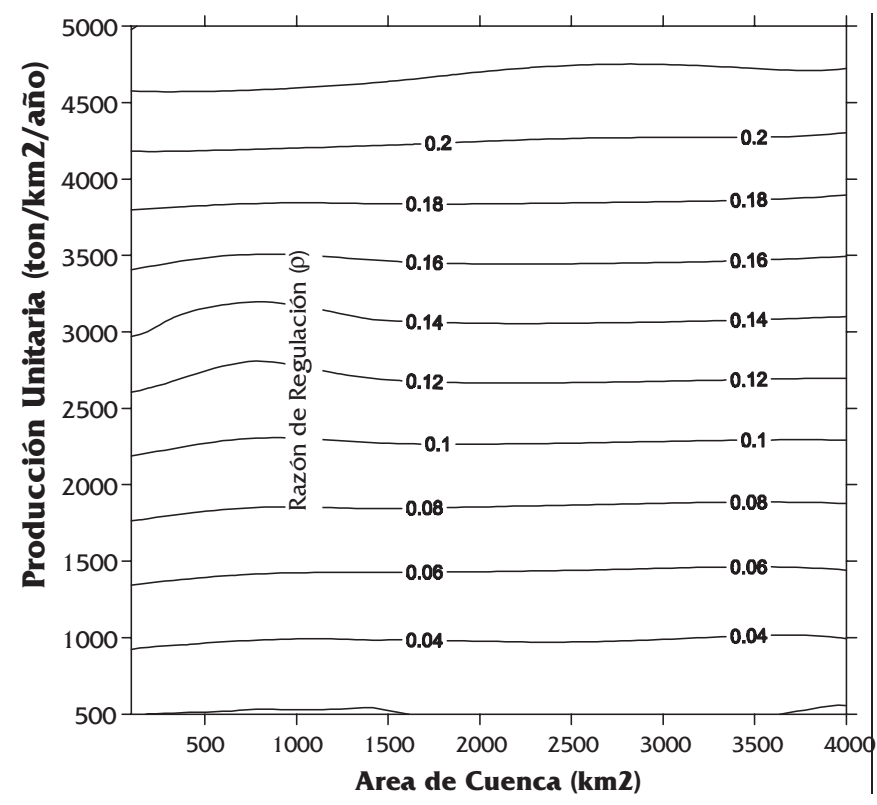

Figura 4. Capacidad de regulación $\left(_{E}\right.$ ) para una vida media de 50 años (para una escorrentía unitaria de 75 $\mathrm{l} / \mathrm{s} / \mathrm{km}^{2}$ )

La cuenca tributaria de $783 \mathrm{~km}^{2}$ tiene una precipitación media de $2781 \mathrm{~mm}$ pero con valores máximos que superan los $7500 \mathrm{~mm}$. Aunque un porcentaje importante de la cuenca de alrededor del $50 \%$ presenta cobertura boscosa, existen zonas sometidas a severa erosión, especialmente en las faldas del Volcán Irazú, así como otras con erosión moderada en la cuenca media. Por otra parte, debido a las altas pendientes existentes, y a las condiciones geológicas, los fenómenos de movimientos en masa son importantes, aun en la parte de la cuenca cubierta de bosque (Parque Nacional Tapantí).
Luego de pocos años de operación se empezaron a tener problemas por la acumulación de sedimentos en las cercanías de la toma de aguas. En octubre de 1973 se decidió vaciar el embalse a través de la descarga de fondo, con la idea de limpiar los sedimentos acumulados, que de lo contrario en poco tiempo habrían inutilizado por completo la planta. Esta operación fue muy exitosa, por lo que se ha realizado durante la época lluviosa casi todos los años (26 veces hasta el año 2003). Ello ha permitido descargar una gran parte de los sedimentos acumulados y mantener el volumen del embalse, que se estima actualmente de unos 42 millones de $\mathrm{m}^{3}$ (un $78 \%$ del volumen original).

El vaciado del embalse se hace en dos etapas: el vaciado lento y el vaciado final. La primera comprende la disminución del nivel del embalse hasta la cota $960 \mathrm{msnm}$ (nivel mínimo de operación). Esto se hace a razón de un metro cada 24 horas por lo que toma unos 30 días. Durante esta etapa los sedimentos que se descargan son pocos y las concentraciones de sedimentos resultantes no son muy diferentes a las que se presentan durante avenidas naturales del río. Una vez terminada la etapa de vaciado lento se abre la compuerta de fondo para desalojar todo el volumen de agua que queda en el embalse, lo cual requiere aproximadamente unas 5 horas hasta el momento en que el río empieza a escurrir libremente dentro del embalse. El período durante el cual el río se deja escurrir libremente es de 30 a 40 horas. Durante esta etapa el río arrastra gran cantidad de sedimentos que remueve a su paso por el embalse vacío.

La descarga máxima de sedimentos ocurre casi inmediatamente después del vaciado completo del embalse durante un lapso de 3 a 5 horas, cuando la concentración de sedimentos alcanza un pico de entre 200000 y 400000 ppm,

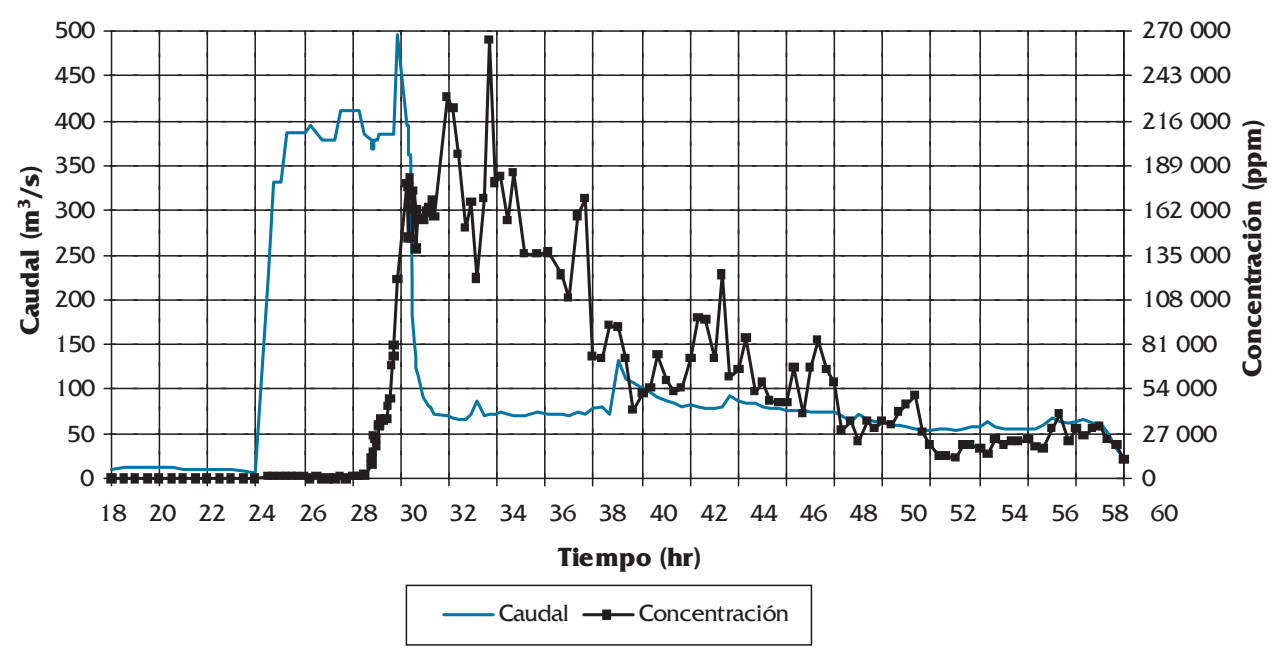

Fig. 5 Caudales y concentración de sedimentos durante vaciado de Cachí del año 2002 
medidos en la Estación El Congo (unos 5 km aguas abajo de la cortina). Después de este pico de sedimentos, el arrastre continúa de forma importante por 1 o 2 días, aunque con concentraciones menores, de entre 15000 y 25000 ppm. Esto se ilustra en la Figura 5 que corresponde al vaciado del año 2002.

En la Figura 6 se muestra los sedimentos descargados en aquellos vaciados en los cuales se tomaron muestras que permitieron hacer estimaciones de la cantidad total descargada. Antes del año 1983 las estimaciones se hacían de forma muy aproximada por lo que los valores reportados no son confiables. La figura muestra también el resultado de los muestreos tomados en la Estación Angostura, que se llevan a cabo desde 1992. La Planta Angostura entró a operar a finales del año 2000 , y desde al año 2001 se vacía en conjunto con el embalse de Cachí, como se comenta más adelante.

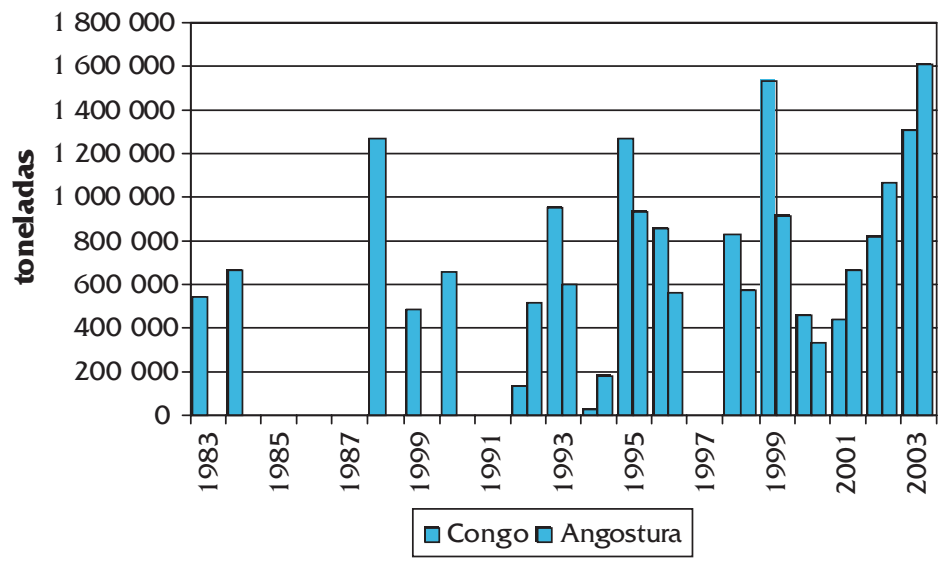

Fig. 6 Sedimentos descargados durante vaciados de Cachí

Estos resultados ilustran la gran variabilidad en la cantidad de sedimentos desalojados, que ha oscilado desde menos de 100000 t hasta más de 1500000 t. Este comportamiento tiene su explicación en dos puntos principales:

- La cantidad de sedimentos que ingresan año con año al embalse es muy variable y está fuertemente afectada por la magnitud y características de las crecientes que se hayan presentado durante el año previo, así como de la existencia o no de fenómenos de movimientos en masa.

- La eficacia de los desembalses varía mucho en función de la duración del proceso, de la cantidad de sedimentos depositados en el embalse, y muy especialmente de los caudales naturales que se presenten durante el vaciado.
En el trabajo de Jansson \& Rodríguez (1992) se analizó con gran detalle el año 1989-1990, para el cual se hizo un balance de la sedimentación del embalse. Según este balance, en ese año ingresaron 919,000 toneladas de sedimentos al embalse, de las cuales $133000(14 \%)$ pasaron directamente a través de los vertedores y conducciones, 133000 (14\%) se depositaron permanentemente en el delta y las terrazas superiores, y $653000(71 \%)$ se desalojaron durante el vaciado. Este último resultado ilustra la gran efectividad de los vaciados, gracias a los cuales se logra limpiar casi el $80 \%$ de los sedimentos depositados. La densidad seca total medida de estos sedimentos es de alrededor de 0.6 ton $/ \mathrm{m}^{3}$, correspondiente a una densidad húmeda total de 1.4 ton $/ \mathrm{m}^{3}$.

Si no se realizan vaciados la agradación progresiva del embalse empezará a afectar el suministro de agua a la central. Es difícil predecir cuantos años se puede operar sin llegar a tener problemas pues en el pasado se han presentado situaciones en las cuales una sola creciente muy grande provocó ingresó de materiales al túnel. Es muy posible que luego de dos períodos de no hacer desembalses los sedimentos empiecen a ser absorbidos por la toma y las turbinas empiecen a verse afectadas por la erosión. Estimaciones aproximadas indican que si no se realizan limpiezas, se perdería la mitad del volumen del embalse en unos 20 años. Por el contrario, con limpiezas como las que se han venido realizando, con remociones de $1000000 \mathrm{~m}^{3}$ por año (600 000 t), en los próximos 40 años se perdería apenas un $15 \%$ del volumen adicional.

Los resultados anteriores indican la gran importancia que los vaciados tienen, no solo para conservar el volumen del embalse, sino para permitir la operación de la planta, que de otra forma en unos pocos años quedaría inutilizada. A pesar de lo anterior, es claro que los vaciados producen impactos ambientales de consideración, como se explica adelante.

\section{Embalse de Angostura}

La planta hidroeléctrica Angostura aprovecha las aguas del río Reventazón, las que son desviadas mediante una presa de enrocamiento de $38 \mathrm{~m}$ de altura. Una conducción mediante túnel y tubería, permite generar $180 \mathrm{MW}$. Aguas arriba de esta planta se encuentran en operación las plantas Río Macho, y Cachí, y una nueva central, La Joya, actualmente en construcción (ver Fig. 7). Todas estas plantas tienen una capacidad combinada de 450 MW y representan un $22 \%$ de la capacidad de generación de Costa Rica. 


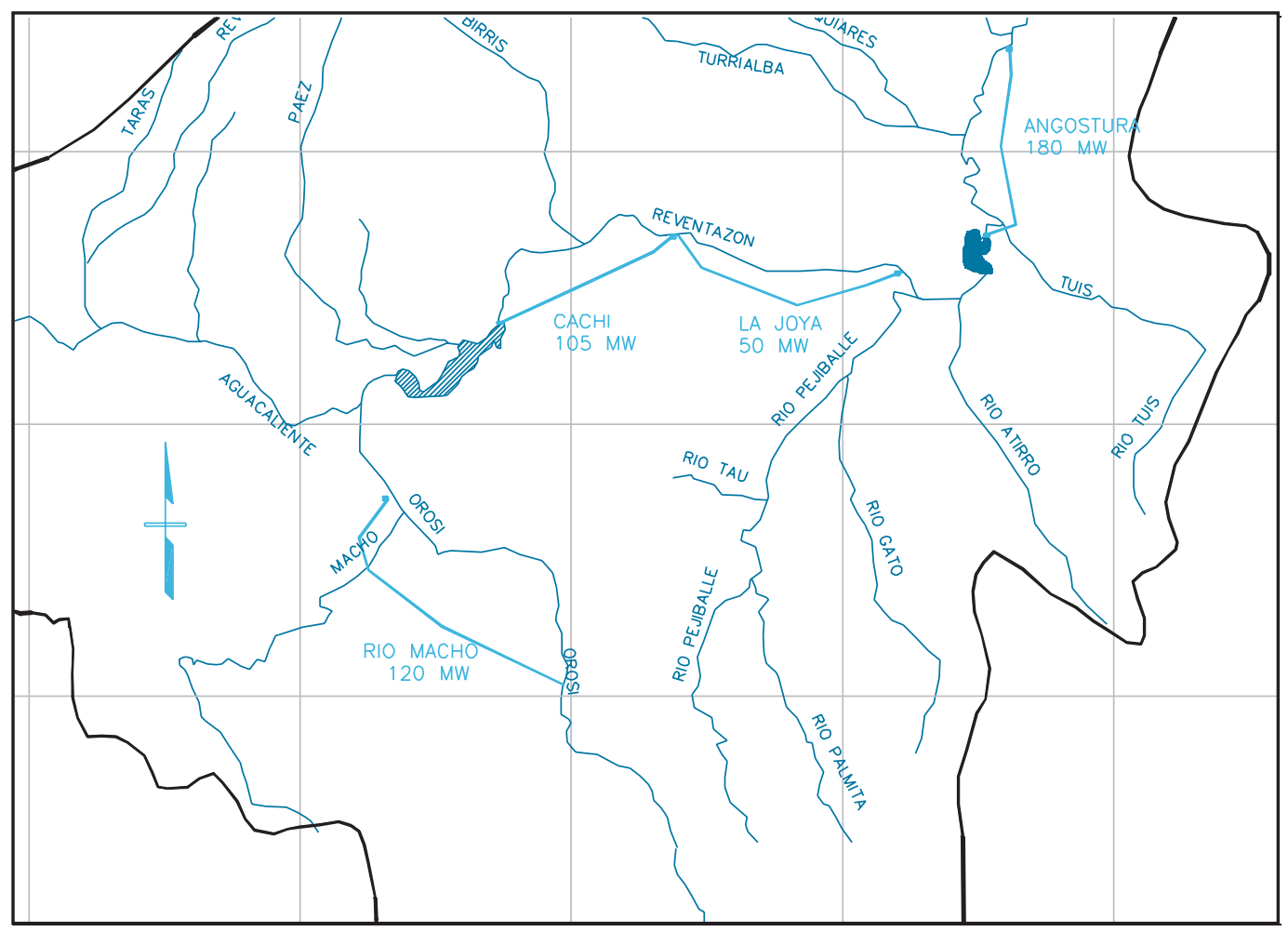

Figura 7. Localización de hidroeléctricas en la cuenca del Reventazón

El P.H. Angostura ha sido concebido como una planta de filo de agua con regulación diaria. Esto significa que se debe contar con un embalse que sea capaz de almacenar agua diariamente (durante la noche u horas de baja demanda), para operar a potencias altas en las horas de mayor demanda. Para lograr esta regulación, y poder lograr la potencia de la planta durante la época seca, es necesario contar con un embalse útil de al menos $2.5 \mathrm{hm}^{3}$. El volumen total inicial del embalse es de unos $17 \mathrm{hm}^{3}$, de los cuales unos $11 \mathrm{hm}^{3}$ corresponden al volumen útil, entre las cotas 570 y $577 \mathrm{msnm}$.

La cuenca del río Reventazón se caracteriza por sus altas pendientes, con cambios de elevación de más $3000 \mathrm{~m}$ en una distancia relativamente corta de unos $60 \mathrm{~km}$ hasta el sitio de la derivación. Asimismo, el clima es de altas precipitaciones con un promedio anual de $3500 \mathrm{~mm}$, y máximos que superan los $6000 \mathrm{~mm}$.

Aunque un porcentaje importante de la cuenca (casi un 50\%) está cubierto de bosques, algunos con muy buen estado de conservación, el río arrastra una carga de sedimentos en suspensión, en su paso por el proyecto, estimada en unos 3.0 millones de toneladas anuales. Para complicar la situación, como se mencionó, anualmente se realizan vaciados de limpieza de la central Cachí, que aportan, en cuestión de un par de días, unas $500000 \mathrm{t}$ de sedimentos adicionales, la mayoría de las cuales es acarreada río bajo los $15 \mathrm{~km}$ que separan ambas plantas.

Además de los sedimentos en suspensión, se presenta un arrastre importante de carga de fondo, cuya cuantificación aproximada indica que representa alrededor de un 10\% de la carga suspendida. La Fig. 8 muestra una estimación de la cantidad de sedimentos en suspensión histórica en el sitio de la estación Angostura, para el período 1967-2000, obtenida a partir de muestreos de sedimentos y su correlación con los caudales líquidos.

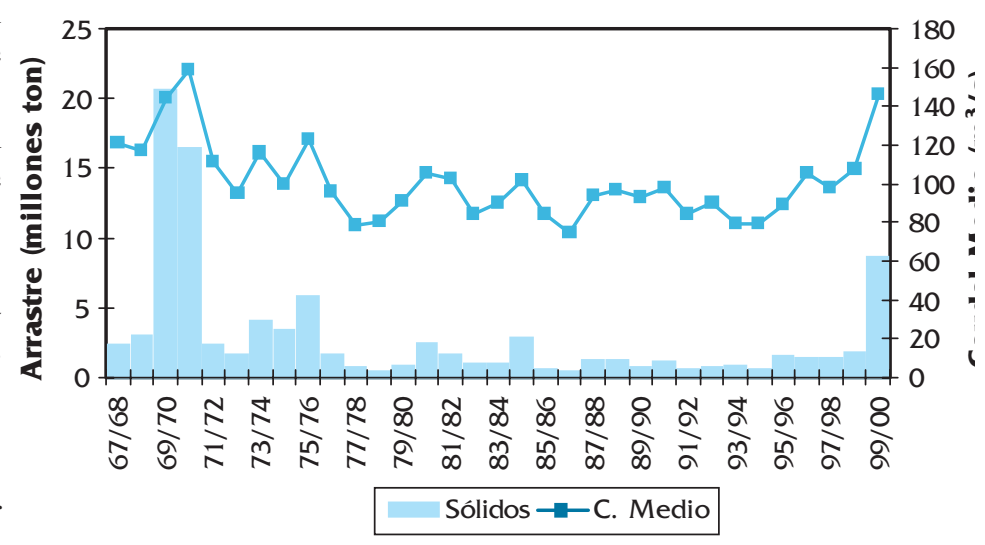

Figura 8. Caudal Medio y Arrastre Anual de Sedimentos 
Se puede observar que mientras los caudales medios oscilan entre 74 y $158 \mathrm{~m}^{3} / \mathrm{s}$, los arrastres en suspensión lo hacen entre 0.6 y 20 millones de toneladas. Este se debe a que el arrastre en suspensión es una función potencial del caudal, y en años muy húmedos, tales como el 69-70 y el 70-71, el arrastre resulta más de 5 veces mayor que en años promedios. De hecho, 1 o 2 avenidas extraordinarias, como las ocurridas en dichos años, son capaces de arrastrar en pocos días tantos sedimentos como los que ocurren en todo un año de escorrentía normal. Los caudales líquidos más frecuentes oscilan entre 50 y $130 \mathrm{~m}^{3} / \mathrm{s}$ (el caudal medio es $101 \mathrm{~m}^{3} / \mathrm{s}$ ), y constituyen más del $67 \%$ de la escorrentía anual. Sin embargo, estos caudales prácticamente no aportan arrastre sólido, pues contribuyen con apenas un 25\% del arrastre. Los vaciados de Cachí contribuyen en cerca de un $22 \%$ de los sedimentos en suspensión.

Como se mencionó, durante estas operaciones de vaciado de Cachí se descarga una onda de sedimentos cuando la concentración de sedimentos alcanza máximos del orden de los 300000 - 400000 ppm. Esta onda toma unos 220 minutos en llegar desde la presa de Cachí a la Estación Angostura. Sin embargo, a lo largo de este trecho el pico de sedimentos se amortigua, y la concentración disminuye a valores del orden de 150000 $\mathrm{ppm}$. Aún así, durante las primeras 12 horas luego de vaciado llegan a la Est. Angostura casi 300000 toneladas. Después de este pico de sedimentos, el arrastre continúa de forma importante por $1 \mathrm{o}$
2 días, aunque con concentraciones menores de entre 15000 y 25000 ppm.

La Figura 9 muestra una planta del embalse de Angostura. Como se observa, una gran parte del embalse útil se encuentra en una zona plana aguas arriba, en donde de forma natural el río ha formado ramificaciones o trenzas. Esta zona se encuentra en su gran mayoría entre las cotas 570 y $577 \mathrm{msnm}$. A su vez, es la parte del embalse en la que el flujo disminuye su velocidad, y en donde con más certeza se depositarán los sedimentos que ingresen al embalse.

El cálculo de la forma en que se depositan los sedimentos a lo largo de los años de operación es bastante complicado, debido a la incertidumbre en cuanto al ingreso real de sedimentos, que como se expuso es muy variable año a año, y principalmente por la geometría del embalse, en el cual los flujos serán tridimensionales, y por lo tanto muy difíciles de modelar o calcular. A pesar de lo anterior, se aplicaron 4 procedimientos de cálculo para estimar como evolucionará el embalse, desde métodos muy simples hasta métodos numéricos tridimensionales:

- Método semi-empíricos de Brune-USBR

- Método unidimensional HEC-6 del Corps of Engineers

- Método bidimensional RESP (Lovoll 1995)

- Método tridimensional SSIIM (Lovoll 1995, Olsen 1994)

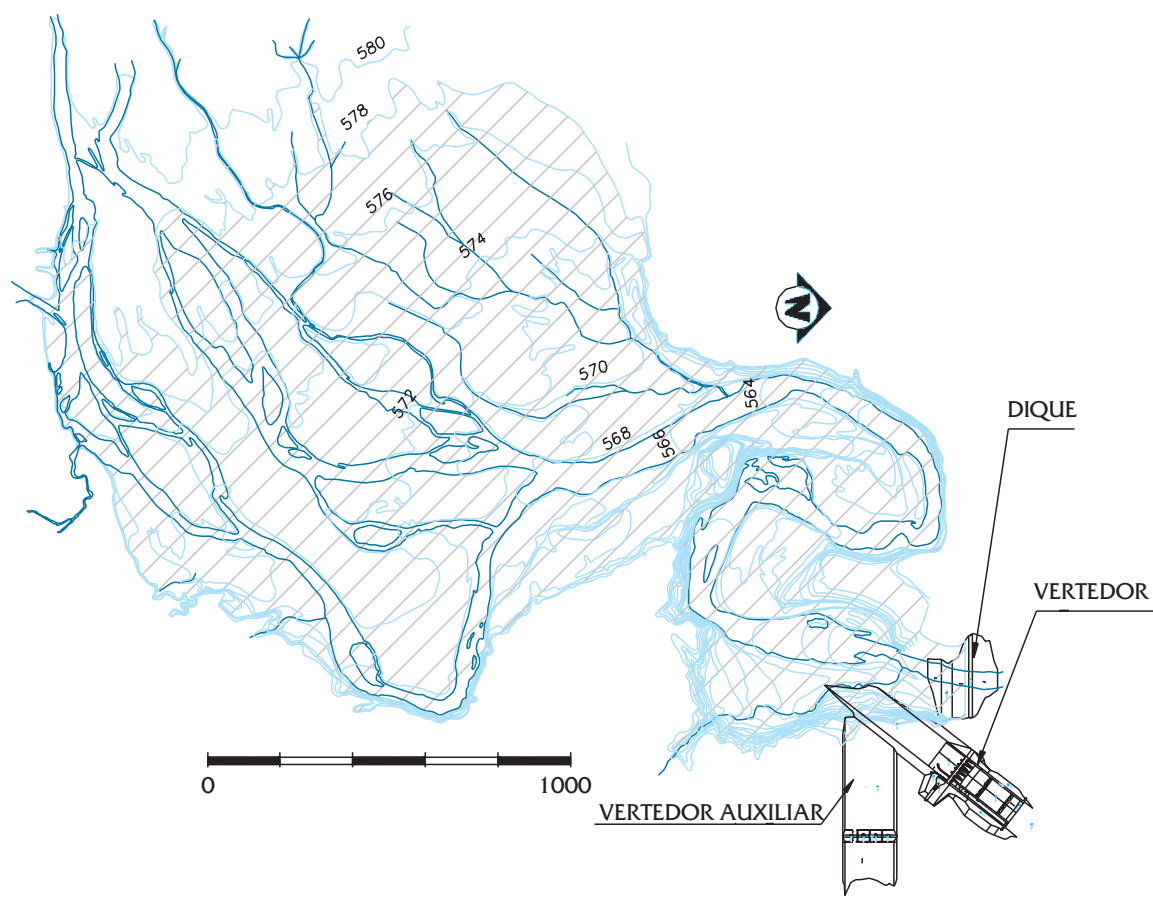

Figura 9. Embalse del P.H. Angostura, vista superior 
De los procedimientos anteriores vale la pena destacar el modelo tridimensional SSIIM, desarrollado por Olsen (1994). Este resuelve las ecuaciones de Navier Stokes en tres dimensiones sobre una malla estructurada, utilizando el modelo k-epsilon para representar las viscosidades turbulentas. La discretización de los términos convectivos se realiza mediante volúmenes de control junto con esquema de ley de potencia o "upwind" de segundo orden. El método SIMPLE se utiliza para la corrección de la presión. La solución es implícita. De este modelo se obtiene el campo de velocidades. Luego las velocidades se utilizan para resolver la ecuación de convección-difusión para cada una de las fracciones o tamaños de los sedimentos considerados. De esta forma se puede obtener la eficiencia de atrape y el patrón de deposición de los sedimentos. Para el caso del embalse de Angostura se utilizó una malla de 54 × 9 × 11, para un total de 5000 celdas. Debido a la gran cantidad de cálculos requeridos en un modelo de este tipo, y al largo período de tiempo que se deseaba simular (30 o 40 años), se realizaron varias simplificaciones:

- Se mantuvo un ingreso constante de sedimentos año a año.

-El hidrograma de caudales y sedimentos se simplificó a un solo caudal de $350 \mathrm{~m}^{3} / \mathrm{s}$, correspondiente a una avenida con período de retorno de un poco menos de 1 año, pero que representa de forma general el patrón de flujo en avenidas.

- Se supuso un nivel constante del agua por lo que el efecto de la operación del embalse o de las limpiezas anuales no se simula.

- No se simuló la erosión debido a los vaciados o cambios en el nivel.

- Granulometría constante a lo largo del tiempo y representada por tres tamaños

- Incrementos de tiempo grandes, de 1.4 años. Entre este lapso, la sedimentación del lecho se realiza con tiempos de cálculo pequeños, utilizando una rutina que escala la deposición de acuerdo al patrón de sedimentación por un factor de 1000 o mayor. Si parte de los depósitos "llenan" el embalse a un nivel superior que el nivel del agua, los sedimentos se redistribuyen en las celdas vecinas por un procedimiento heurístico.

La Figura 10 muestra los cambios en la eficiencia de atrape y el volumen efectivo remanente del embalse, mientras que la Figura 9 muestra el patrón de velocidades y reducción en el tamaño del embalse.

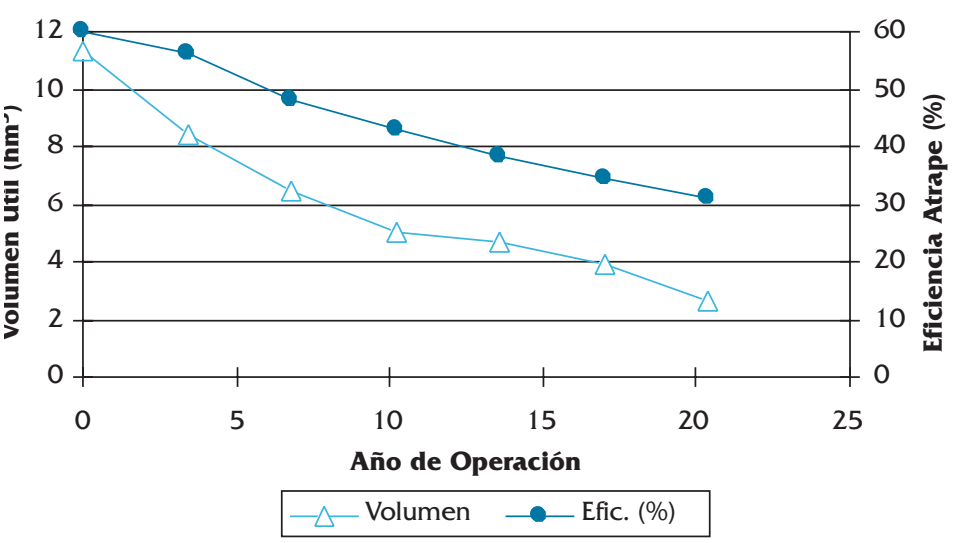

Figura 10. Variación del volumen útil y eficiencia de atrape, modelo SSIIM
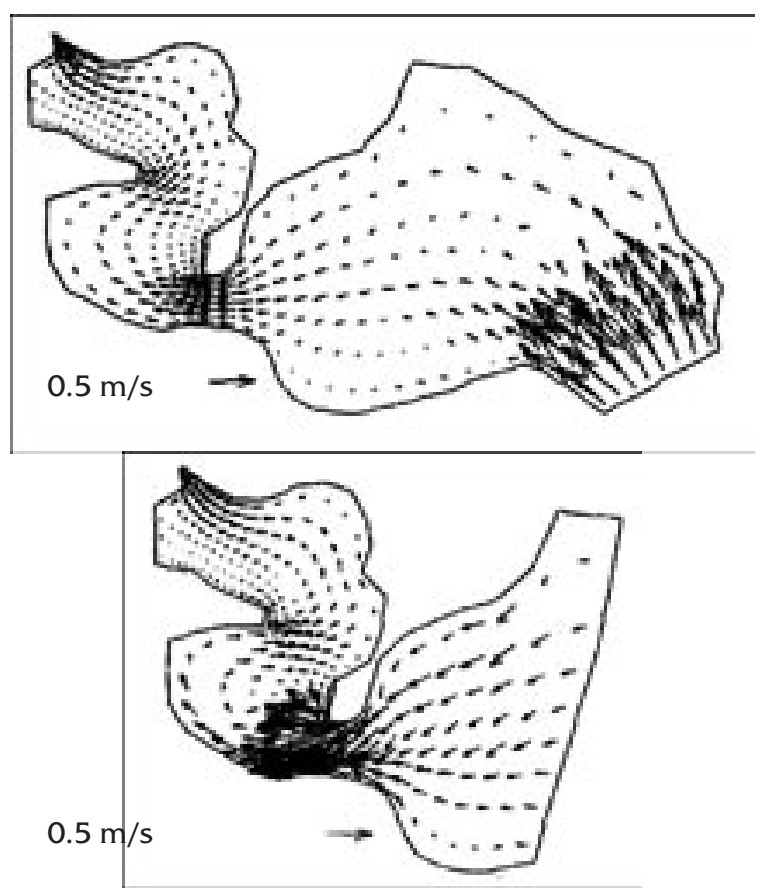

Figura 11. Velocidad superficial, modelación con SSIIM, izquierda: condición inicial, derecha: luego de 7 años

Se propusieron tres políticas de operación que deberán seguirse con el fin de minimizar el impacto de la sedimentación en el embalse:

a) operación a niveles bajos durante la época húmeda,

b) vaciado y limpieza del embalse, y

c) establecimiento de un sistema de monitoreo continuo de la evolución de la sedimentación en el embalse mediante batimetrías.

El objetivo de la operación a niveles bajos en la época húmeda es minimizar la deposición de sedimentos en el volumen útil del embalse, entre las cotas 577 y $570 \mathrm{msnm}$, puesto que cuando se 
opera en estas cotas, las deposiciones ocurrirán en la zona aguas arriba del embalse, muy ancha y de poca profundidad. En esta zona las limpiezas anuales mediante el vaciado del embalse no serán efectivas para arrastrar los sedimentos que se depositen.

En un año típico los caudales menores a 90 $\mathrm{m}^{3} / \mathrm{s}$ son responsables de menos del $6 \%$ de los sedimentos arrastrados; entre 90 y $110 \mathrm{~m}^{3} / \mathrm{s}$ se arrastran otro $11 \%$ adicional, y el intervalo entre 110 y $160 \mathrm{~m}^{3} / \mathrm{s}$, responde a un $20 \%$ adicional. Se propone entonces una política de operación del embalse, dependiendo del caudal de ingreso al embalse, mostrada en la Tabla 3.

Tabla 3. Política de Operación, Embalse de Angostura

\begin{tabular}{|c|c|c|}
\hline $\begin{array}{c}\text { Caudal Natural } \\
\mathrm{Q}\left(\mathrm{m}^{3} / \mathrm{s}\right)\end{array}$ & $\begin{array}{c}\text { Nivel Máximo de } \\
\text { Operación }(\mathrm{msnm})\end{array}$ & $\begin{array}{c}\text { Volumen útil } \\
\left(\mathrm{hm}^{3}\right)\end{array}$ \\
\hline$<90$ & 577 & 11.0 \\
\hline $90<\mathrm{Q}<110$ & 575 & 9.0 \\
\hline $110<\mathrm{Q}<160$ & 573 & 3.5 \\
\hline $\mathrm{Q}>160$ & 571 & 1.0 \\
\hline
\end{tabular}

Según estimaciones, con esta política de operación se logra una disminución del $50 \%$ en la deposición de sedimentos en el volumen útil del embalse, con lo que su vida útil se extendería por lo menos 30 años. Con esta operación, la deposición de sedimentos continuará en el volumen útil durante unos 10 a 15 años a un ritmo más o menos constante. Mientras tanto, el volumen muerto disminuirá rápidamente y eso ocasionará menor eficiencia de atrape en el embalse. Luego de cierto tiempo, será necesario hacer una limpieza anual en Angostura, en sincronía con el vaciado de Cachí.

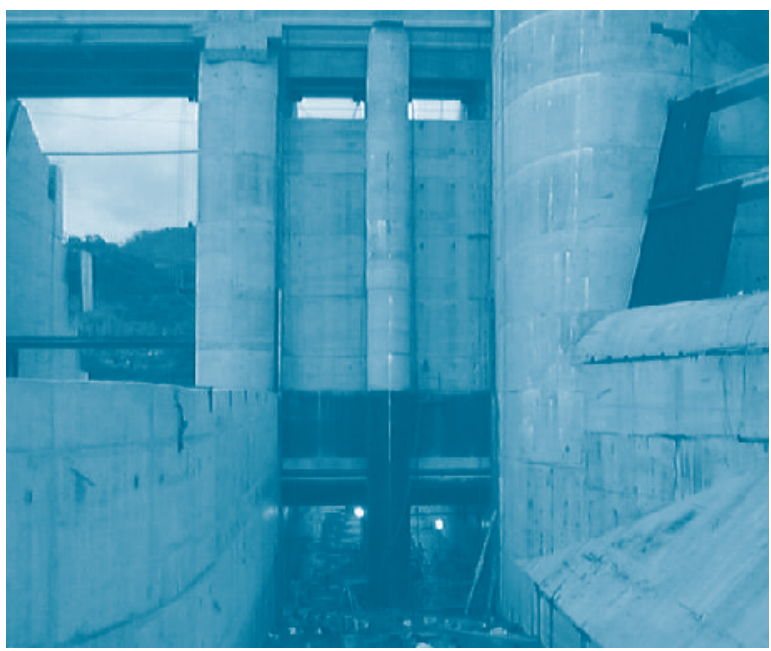

Figura 12. Compuertas de descargas de fondo,.a la derecha, la toma de aguas
Tanto por el problema de los vaciados de limpieza de Cachí, como por la necesidad de realizar limpiezas adicionales, en el diseño del P.H. Angostura se tuvo la precaución de dejar previstas dos compuertas de limpieza, de $4 \mathrm{~m}$ de ancho por $5.5 \mathrm{~m}$ de altura, que se ubican junto a la toma de aguas, a una elevación $13 \mathrm{~m}$ menos que el umbral de la misma, ver Figura 12.

La experiencia en Cachí, como de muchos otros embalses, ha mostrado que el vaciado ha sido particularmente útil en embalses pequeños, en donde es factible vaciar y llenar el embalse en unos pocos días sin pérdida excesiva de generación.

Para tratar de estimar la efectividad de la limpieza mediante las compuertas de fondo, se empleó un modelo semi-empírico de erosión retrogresiva cuya teoría se encuentra en detalle en Fan \& Morris, 1992. Los cálculos se realizaron suponiendo que el embalse se ha sedimentado por completo, hasta la elevación del umbral de los vertedores. Se supuso además que la limpieza se realiza con un caudal en el río de $150 \mathrm{~m}^{3} / \mathrm{s}$, y que la erosión retrogresiva abre un cauce de unos $50 \mathrm{~m}$ de anchura. Los cálculos indican que luego de unas 40 horas de limpieza, el cauce de erosión se extiende unos $2 \mathrm{~km}$ aguas arriba, y la cantidad erosionada excede las 400000 toneladas. Estas estimaciones indican que es factible movilizar cantidades apreciables durante el vaciado y limpieza del embalse, siempre y cuando en el río corran caudales importantes del orden de $150 \mathrm{~m}^{3} / \mathrm{s}$ o más.

La última medida importante para el control de la sedimentación en el P.H. Angostura es un sistema de seguimiento y medición que ya existía para el P.H. Cachí, pero que se ha intensificado desde la puesta en marcha de Angostura.

Dado que Angostura es una central de mucha importancia, los vaciados de los embalses se programan de viernes a domingo; y en sincronía con los de Cachí. Por tratarse de un embalse mucho más pequeño que el de Cachí el proceso de vaciado tarda alrededor de un día, desde que se inicia hasta que llega al escurrimiento libre. Posteriormente se deja al río corriendo libremente por un tiempo que oscila entre 30 y 40 horas.

El monitoreo del embalse se basa fundamentalmente en campañas de sondeo a realizar antes y después de cada desembalse y, si se presentara un evento de gran magnitud (caudales entrantes al embalse mayores a $1500 \mathrm{~m}^{3} / \mathrm{s}$ ) después de éste. 


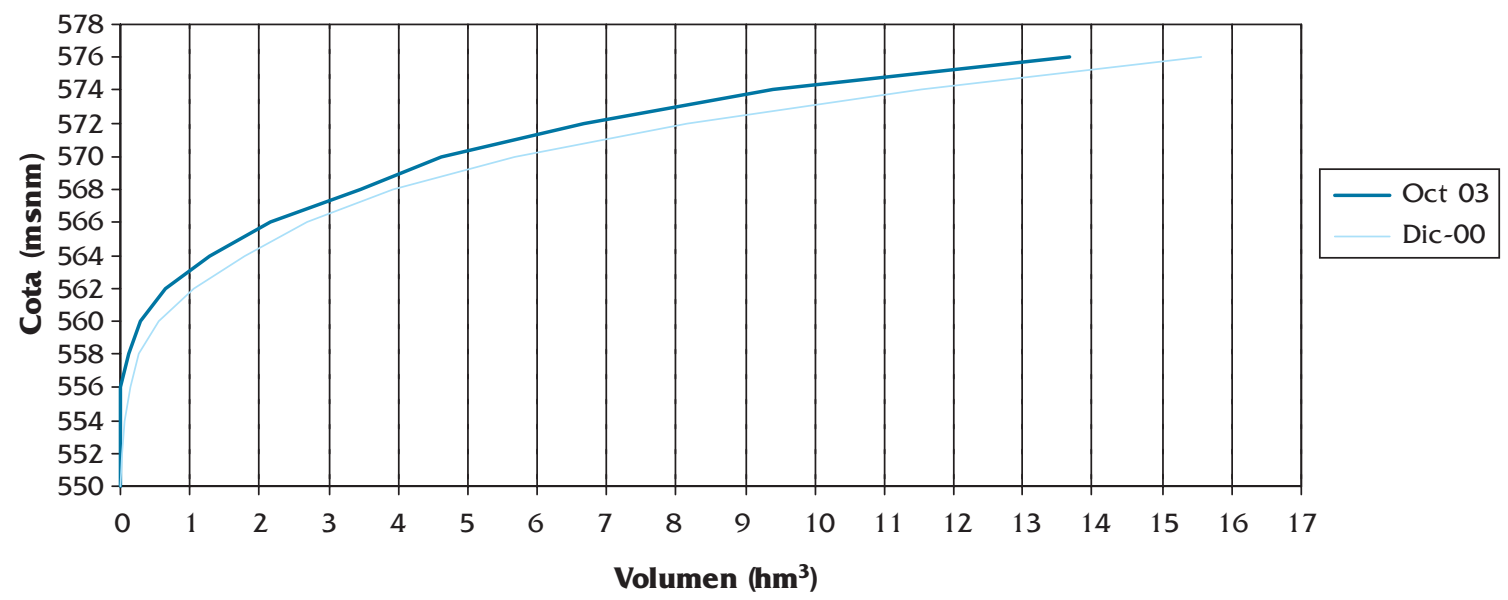

Figura 13. Curvas de volumen versus elevación

A la fecha se han realizado 10 sondeos entre diciembre del 2000 y octubre del 2003. La Figura 13 muestra la evolución de la capacidad del embalse, que muestra una pérdida del $4.4 \%$ durante un período de 3 años.

\section{Impactos Ambientales}

En el caso de los embalses en los cuales se han realizado vaciados de limpieza, como Cachí y Angostura, se ha observado mortandad de especies acuáticas aguas abajo. En la actualidad se están aplicando procedimientos a los fines de cuantificar su importancia, así como evaluar su efecto en el largo plazo. Existen referencias interesantes de cómo se pueden mitigar los efectos de los vaciados de limpieza. Por ejemplo, en Francia uno de los principales impactos observados ha sido la mortandad de peces principalmente por la reducción del oxígeno disuelto en el agua (Morris \& Fan 1997). Otros efectos, como la disminución en la temperatura del agua o el incremento en los niveles de amoniaco, no resultan críticos. Para ello se ha estudiado la resistencia de las especies principales según las concentraciones de sedimentos en suspensión y oxígeno disuelto, de tal forma de tratar que la secuencia de vaciado no exceda ciertos límites.

En todo caso, los impactos ambientales adversos deben considerarse a la luz de las posibles alternativas, como lo sería aceptar la pérdida inevitable de un embalse, lo cual a vez requerirá el uso de otros recursos naturales para la construcción de un nuevo embalse, o el desarrollo y uso de fuentes alternativas de generación, como por ejemplo, de una planta térmica, lo que desde luego tiene también otros impactos importantes, particularmente relacionados con la producción de gases de invernadero y otras sustancias perjudiciales para la salud.

\section{Embalse de Valdesia}

Por su cercanía a la capital de la República Dominicana, y por sus recursos naturales e infraestructura hidráulica, la cuenca del río Nizao constituye uno de los activos más importantes y estratégicos de dicho país. Por medio de sus embalses --Jigüey, Aguacate, Valdesia y las Barías--, se cuenta con un volumen de regulación de más de $300 \mathrm{hm}^{3}$, con una capacidad instalada hidroeléctrica de 204 MW que producen más de 400 GWh anuales de energía limpia, y con un acueducto que ha venido supliendo un $40 \%$ de las necesidades de agua potable de la ciudad de Santo Domingo. En particular, la presa de Valdesia permite el almacenamiento y desvío de las aguas del río Nizao para su aprovechamiento por medio de una central hidroeléctrica (54 MW); de un acueducto que aporta $175 \mathrm{hm}^{3}$ a la zona metropolitana de Santo Domingo; y un sistema de riego a partir del desfogue de las aguas turbinadas en el contraembalse de Las Barías.

\section{La Cuenca del Río Nizao}

La cuenca del río Nizao hasta la presa de Valdesia tiene $887 \mathrm{~km}^{2}$ y presenta precipitaciones medias anuales de entre 1000 y $1500 \mathrm{~mm}$. El caudal medio hasta Valdesia es de $21.4 \mathrm{~m}^{3} / \mathrm{s}$. En la Fig. 14 se muestra la red hidrográfica junto con la ubicación de los cuatro embalses existentes en la cuenca: Jigüey, Aguacate, Valdesia y Las Barías. 
El uso inadecuado de los recursos naturales en la cuenca, donde alrededor del $92 \%$ de su área está formada por colinas y montañas con relieve inclinado a escarpado, ha favorecido el desarrollo de procesos erosivos. Esta situación, asociada a las condiciones de torrencialidad de los sistemas fluviales en estudio y a la severidad climática de la región propicia la ocurrencia de procesos de erosión y sedimentación importantes en la cuenca, los que pueden adquirir magnitudes descomunales durante los eventos hidrometeorológicos mencionados. Los movimientos en masa resultantes de la inestabilidad de laderas, de construcción de caminos y otras tipologías de erosión parecerían tener mucha más importancia en la producción total de sedimentos (Nagle, 2000).

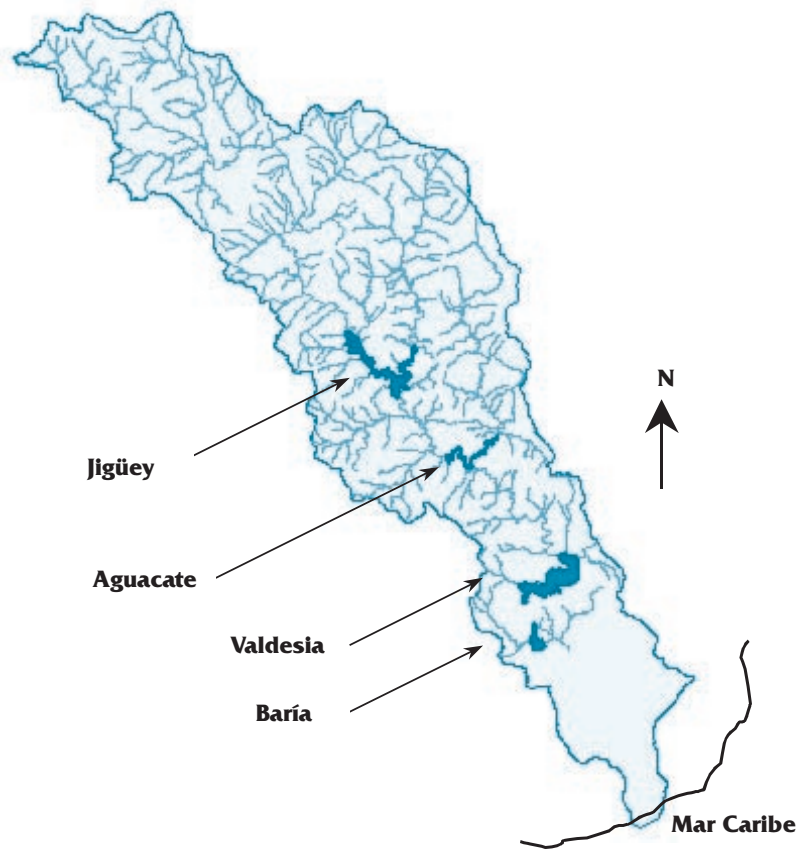

Figura 14. Cuenca del Río Nizao, red hidrográfica y embalses

Las condiciones de conservación de la cuenca, a partir de un proceso acelerado de deforestación hasta los años sesenta, se han logrado estabilizar de forma relativa. En ese sentido, los elementos disparadores de la producción de sedimentos son de tipo meteorológico.

La presa de Valdesia fue la primera gran obra de infraestructura construida en la cuenca, siendo inaugurada en 1976. Consta de una cortina de contrafuertes de $342 \mathrm{~m}$ de longitud de cresta, y una altura de 82 desde su fundación. El nivel de operación normal es la cota $150 \mathrm{msnm}$, mientras que el nivel de cresta la cota $156 \mathrm{msnm}$.
El vertedor está compuesto de 5 compuertas planas de $24 \mathrm{~m}$ de largo por cinco de altura, diseñadas para una avenida con un caudal influente de $7200 \mathrm{~m}^{3} / \mathrm{s}$. En la Fig. 15 se muestra una vista del embalse.

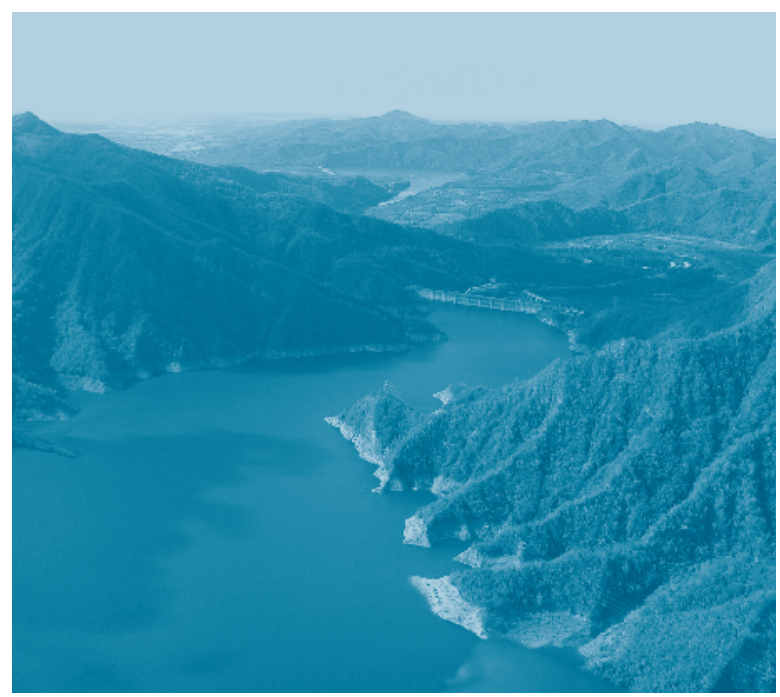

Figura 15. Fotografía de embalse y presa de Valdesia

\section{Procesos de Sedimentación en el embalse de Valdesia}

Una batimetría del embalse de Valdesia realizada luego de la ocurrencia de huracanes David y Federico en 1979 mostró que se habían depositado unos $33 \mathrm{hm}^{3}$ desde la puesta en marcha del proyecto en el año 1976, lo que representa cerca de un $18 \%$ del volumen original de poco más de 185 $\mathrm{hm}^{3}$. Entre otros daños, estos eventos colmataron las dos descargas de fondo de $1.3 \mathrm{~m}$ de diámetro cada una, las cuales hasta el momento no han podido ser rehabilitadas.

En los años siguientes la Corporación Dominicana de Energía (CDE), propietaria de la obra, se abocó a buscar una solución al problema, para lo cual en el año 1984 se firmó un contrato con la empresa italiana Geolidro para el suministro de una draga especialmente diseñada para la situación de Valdesia, que funciona mediante un sistema de sifonamiento que se basa en aprovechar la columna de agua presente en el embalse para producir la descarga de los sedimentos. Está draga finalmente comenzó a operar en 1988, y funcionó de forma sostenida por unos cuatro años, logrando limpiar de sedimentos una zona de unos 200 a 300 $\mathrm{m}$ desde la cortina. Desde entonces, el alto nivel del embalse así como algunos daños menores y falta de algunos repuestos ha impedido que esta máquina continue su trabajo. 
En el año 1992 iniciaron operación las centrales de Jigüey y Aguacate, ubicadas aguas arriba de Valdesia. Particularmente la primera, cuenta con un embalse a la fecha de su inauguración, de $167 \mathrm{hm}^{3}$, aportados por una cuenca tributaria que representa el $60 \%$ de la cuenca hasta Valdesia. Presumiblemente, como se discute en este estudio, estas nuevas obras han reducido el ingreso de sedimentos al embalse de Valdesia a un $30 \%$ del valor original.

Los sedimentos, cuyo volumen actual es del orden de los $50 \mathrm{hm}^{3}$, ocupan un alto porcentaje de la capacidad muerta del embalse de Valdesia y una proporción importante de la capacidad útil. Una de las tomas del acueducto, se encuentra a tan sólo 9 $\mathrm{m}$ de ser alcanzada por el nivel de sedimentos. Por lo tanto, en este momento, la condición del sistema es delicada, pues de mantenerse la tendencia, sobre todo en caso de un nuevo huracán o evento hidro-meteorológico extremo, es posible que el embalse se colmate en una fracción significativa de su capacidad útil de

Como se mostró en la Tabla 2, gracias a batimetrías realizadas en este y otros embalses, se han determinado tasas unitarias de producción entre 1500 y $5000 \mathrm{~m}^{3} / \mathrm{km}^{2} /$ año, valores sumamente altos, producto de combinación de un mal uso del suelo junto con la existencia de eventos hidrológicos extremos. Dichos valores contrastan con los valores supuestos durante la etapa de diseño de los diferentes proyectos, que suponían valores del orden de los $500 \mathrm{~m}^{3} / \mathrm{km}^{2} /$ año.

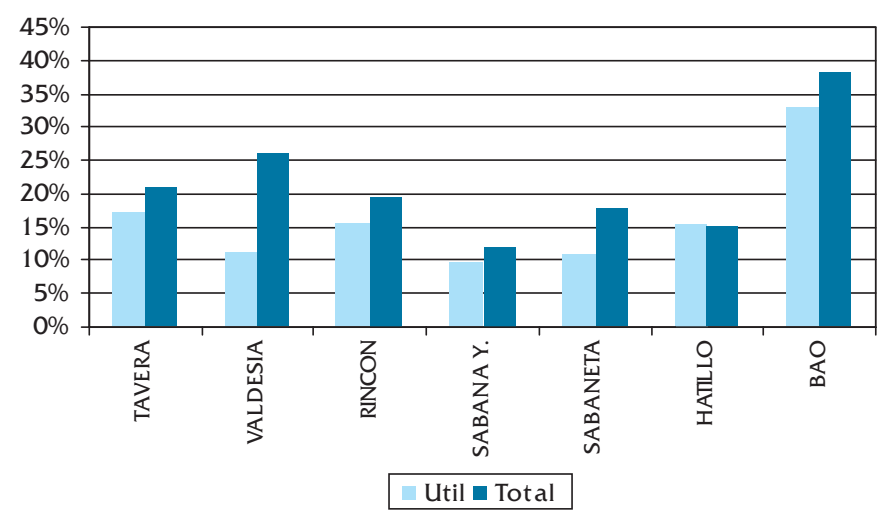

Figura 16. Porcentaje de pérdida de volumen de embalses de la Rep. Dominicana (fuente: INDRHI 1998)

En cuanto al embalse de Valdesia, prácticamente la única información de mediciones sedimentológicas con que se cuenta es la correspondiente a una serie de relevamientos batimétricos realizados en los años 1979, 1981,1991 y en el año 2000. Sobre esta última batimetría sólo se cuenta con información parcial. Estas valiosas mediciones han permitido determinar que existe una alta tasa de sedimentación en la cuenca del Nizao y en general en muchas otras de las cuencas de Rep. Dominicana en las que existen embalses, con una tasa de pérdida de volumen anual promedio del 1.5\% (ver Fig.16).

Los embalses de Jigüey y Aguacate fueron construidos en el año 1992 y tienen áreas de aporte de $541 \mathrm{~km}^{2}$ y $751 \mathrm{~km}^{2}$, respectivamente.

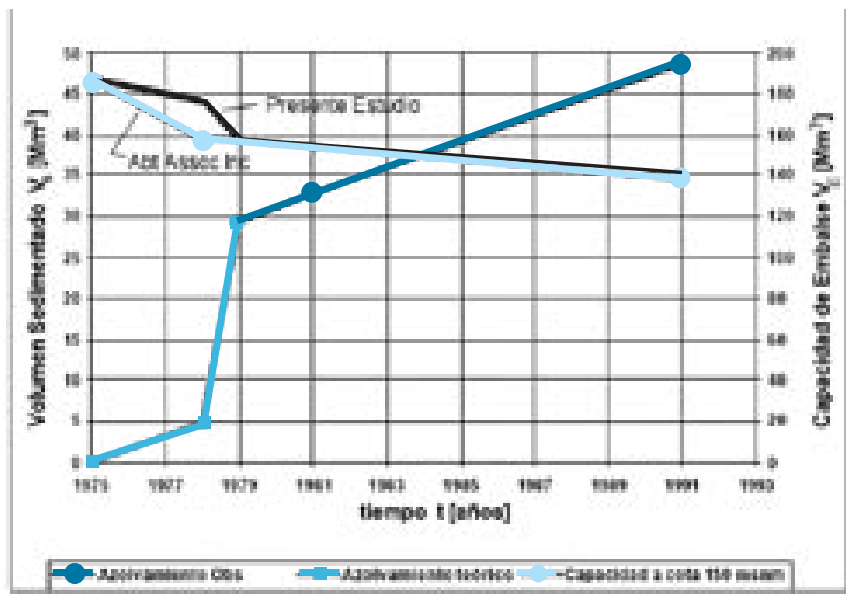

Figura 17. Evolución de la sedimentación en el embalse

La dinámica de la deposición de de sedimentos en el vaso del embalse de Valdesia, se ilustra en la Fig. 17. Aceptando esta posible dinámica del azolvamiento del embalse Valdesia, se concluye que durante 15 años de operación (de los dieciséis transcurridos desde el inicio de su operación hasta 1991) se produjo un volumen de sedimentos del orden del $49 \%$ del total acumulado, lo cual representa una tasa de $1.59 \mathrm{hm}^{3} / \mathrm{año}$; mientras que solo en el año 1979 se produjo un volumen de 24.6 $\mathrm{hm}^{3}$ (51\% del total y del orden de quince veces el promedio anual) debido a las tormentas generadas por el paso de los huracanes David y Federico. El efecto de este azolvamiento se refleja en una reducción de más del $25 \%$ de la capacidad de almacenamiento de este embalse.

La tasa de acumulación de 1.59 hm³/año, que no considera el efecto de los huracanes David y Federico, equivale a una producción específica de 1600 ton $/ \mathrm{km}^{2} /$ año, lo cual es un valor usual en países tropicales en áreas hidrológicas sin anomalías significativas, en el sentido que el ritmo de acumulación va progresivamente disminuyendo a medida que el vaso se va colmatando y disminuye su eficiencia de retención de materiales sólidos. 
Tanto los caudales líquidos como los caudales sólidos en el sistema hidrográfico del Nizao fueron estimados mediante el modelo SWAT (Arnold 2001, Abt Assoc. Inc. 2002). SWAT es un modelo desarrollado para cuantificar el impacto de las prácticas de manejo en cuencas complejas, desarrollado por el USDA. Este tipo de modelo tiene una base física, pues utiliza información específica sobre el clima, suelos, topografía, vegetación, uso de la tierra, y prácticas de manejo. La calibración de este modelo se hizo seleccionando un grupo de años que no estuviera afectado por el paso de huracanes y el criterio de calibración consistió en tratar de reproducir la producción promedio anual estimada a través de la información batimétrica levantada en el embalse de Valdesia. La Fig. 18 muestra los valores finalmente utilizados, los cuales consideran además la contribución extraordinaria de los huracanes David y Federico, que según la discusión anterior pueden haber generado unos $24 \mathrm{hm}^{3}$, aunque el modelo SWAT da un valor en el orden de los $10 \mathrm{hm}^{3}$.

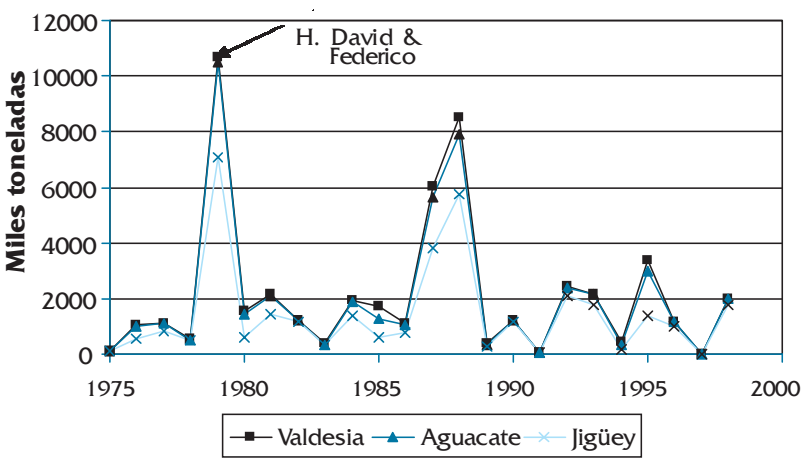

Figura 18. Producción de sedimentos período 1975-1998 (fuente: Abt Assoc. Inc., 2002)

Debido a la escasez de datos se decidió utilizar una serie de procedimientos empíricos para la estimación de la evolución de la sedimentación en los embalses del sistema: uno desarrollado por los autores basado en una ecuación de eficiencia de atrape de sedimentos del tipo Brune, y otro aplicando un modelo matemático basado en el método de reducción de áreas, desarrollado por el HR Wallingford Group del Reino Unido denominado RESSASS (1996) .

La Fig. 19 muestra la estimación de la variación del volumen total del embalse de Valdesia. La simulación se inicia en el año 1975, y hasta 1992 se supone que todos los sedimentos llegan al vaso. Posteriormente se toman en cuenta los sedimentos atrapados en los dos embalses de aguas arriba. El volumen total inicial de $186 \mathrm{hm}^{3}$ se ha reducido a un $75 \%$ del volumen inicial en el año 2002, a un $67 \%$ en al año 2015 y a un $65 \%$ en el año 2025 . De la estadística de la afectación por huracanes, esta estimación supone que del presente al 2027 se presentarán dos eventos similares a los del año 79 (David). También en la figura se muestran los resultados de las tres batimetrías realizadas hasta el momento (1979, 1981 y 1991), las cuales comparan bastante bien con los resultados del modelo.

Embalse de Valdesia, R.D.

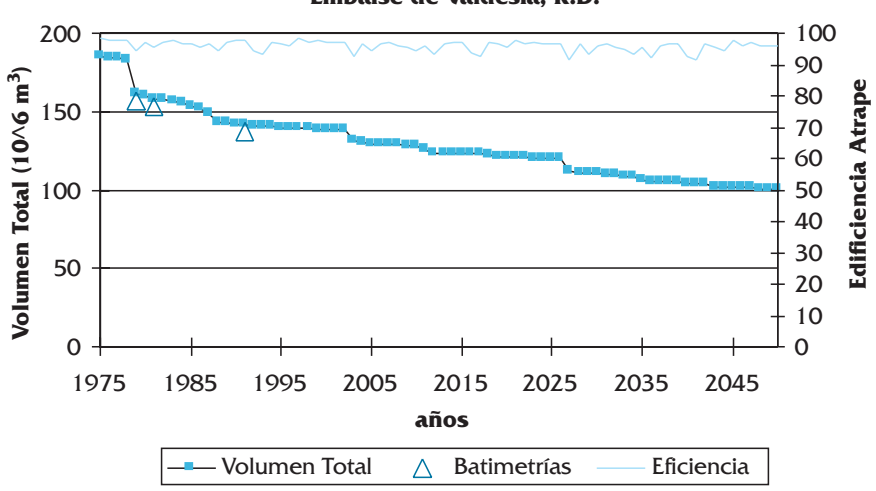

Figura 19. Futura evolución del Embalse de Valdesia

Un resultado muy interesante es que la tasa de aporte de sedimentos al embalse se redujo a un $30 \%$ de la original con la entrada en operación del embalse de Jigüey. Según estos resultados, la tasa de acumulación se redujo de $2.4 \mathrm{hm}^{3}$ anuales a $0.65 \mathrm{hm}^{3}$.

\section{Control de la Sedimentación}

El análisis de las diversas opciones que existen para controlar los sedimentos en el embalse de Valdesia indican que la medida más importante ya se hizo, con la construcción del embalse de Jigüey aguas arriba. A corto plazo la única opción viable adicional para la remoción de un porcentaje significativo de los sedimentos que finalmente llegan al embalse es la del dragado. Para ello se está ejecutando un proyecto para la rehabilitación y puesta en marcha de la draga Geolidro, con lo cual se procedería a la limpieza de los primeros $500 \mathrm{~m}$, y posteriormente llegar hasta el primer kilómetro desde la cortina. La cantidad a remover sería del orden de los $2 \mathrm{hm}^{3}$. El plazo de ejecución sería de entre tres y cuatro años, según la productividad que se logre.

\section{Conclusiones}

En zonas tropicales como es el caso de Costa Rica y la Rep. Dominicana, el problema de la sedimentación afecta especialmente a los embalses con razones de almacenamiento $\mathrm{Kt}<100-80$. 
Por falta de información, muchas de los embalses construidos en estos países no consideraron la alta producción de sedimentos de las cuencas, en el rango de 1500 a $5000 \mathrm{t} / \mathrm{km}^{2} /$ año.

En el caso de los embalses de Angostura y Cachí prácticamente la única forma de disminuir la pérdida de volumen es mediante vaciados completos realizados anualmente. Sin embargo, hay que reconocer que esta práctica tiene afectaciones ambientales que apenas se están cuantificando.

El embalse de Valdesia ilustra una situación muy poco estudiada en la literatura técnica, cual es el efecto en la producción de sedimentos y en la sedimentación de embalses de eventos hidrológicos extremos tipo huracanes. Se muestra también como, por la falta de información detallada relativa a la producción de sedimentos, con los datos de batimetrías es posible calibrar modelos de producción de sedimentos, así como la aplicación de técnicas sencillas para la predicción del comportamiento de embalses en esas circunstancias.

El manejo de los sedimentos se debe hacer de forma integral: origen, transporte por los ríos, tránsito dentro en los embalses y traslado aguas abajo hasta el mar; por lo que debe ser mediante planes interinstitucionales y sociales. Sin embargo es cierto que las medidas para disminuir la producción de sedimentos en la cuenca son de alto costo, y de impacto a muy largo plazo.

\section{REFERENCIAS BIBLIOGRÁFICAS}

AB Hydroconsult, (1995), Sedimentation and Erosion Processes related to the H.E. Projects Angostura, Guayabo and Siquirres, Part 1, AB Hydroconsult, Uppsala, Sweden

Abt Associates Inc., (2002), Montaje y Aplicación del Modelo Hidrológico SWAT en la Cuenca del Río Nizao, PROMATREC, INDRHI.

Arnold J.G., et al., (2001), SWAT. Soil and Water Assessment Tool. USDA Agricultural Research Service. Soil and Water Research Laboratoty. Temple, Texas. USA.

Brune, G.M. (1953), Trap Efficiency of Reservoirs, Trans. AGU, vol 34, n 3

Churchill, M.A. (1948), Discussion of "Analysis and Use of Reservoir Sediment Data", by L.C. Gollschalk, Procc of Federal Ingeragency Sedimentation Conference, USA.

Fan, J., Morris, G.L. (1992), "Reservoir sedimentation II: reservoir desiltation and long-term storage capacity", Jour. of Hyd. Engrg., vol 118, no 3, March.
HR Wallinford, (1996), Measuring and Prediction Reservoir Volume Changes due to Sedimentation: RESSASS Versión 1.1, User Manual.

Lovoll, A. (1994), Calculation of water and sediment flow in the Angostura Reservoir, Costa Rica, University of Trondheim, Norway

Morris, G. L. \& Fan, J., (1997), Reservoir Sedimentation Handbook. Design and Management of Dams, Reservoirs and Watersheds for Sustainable Use. McGrawHill Book Co., NY, USA.

Nagle, G. N., (1999), "Los efectos de un huracán sobre la pérdida de suelos en parcelas cultivadas en una cuenca tropical de montaña". Dept. de Recursos Naturales, Univ. de Cornell, Ithaca, NY, USA.

Olsen, N.R. (1994), "SSIIM-A three dimensional numerical model for simulation of water and sediment flow", Hydrosoft-94, Porto Carras, Greece.

Olsen, N. R. B. (2003) "3D CFD Modeling of a Self-Forming Meandering Channel", ASCE Journal of Hydraulic Engineering, No. 5, May

Rodríguez, A., Jansson, M. (1992), Estudios Sedimentológicos en el Embalse de Cachí, Costa Rica, ICE

Tan, Y., (1994), Reservoir Design and Management to Control Sediment, Panel ICCORES, Saint Peterburg, Rusia.

Walling D.E., Webb B.W. (1996), Erosion and Sediment Yield: a global overview, IAHS Publication No. 236, Wallingford, UK

White, R. (2001), Evacuation of Sediments from Reservoirs, HR Wallingford, Thomas Telford Publishing, UK. 
